\title{
Are pretreatment neutrophil-lymphocyte ratio and platelet- lymphocyte ratio useful in predicting the outcomes of patients with small-cell lung cancer?
}

\author{
Min Deng ${ }^{1,2, *}$, Xuelei Ma ${ }^{1,2, *}$, Xiao Liang ${ }^{1,2}$, Chenjing Zhu' ${ }^{1,2}$, Manni Wang ${ }^{1,2}$ \\ ${ }^{1}$ Cancer Center, State Key Laboratory of Biotherapy, West China Hospital of Sichuan University, Chengdu, Sichuan, PR China \\ ${ }^{2}$ Department of Oncology, West China Hospital of Sichuan University, Chengdu, Sichuan, PR China \\ *These authors contributed equally to this work
}

Correspondence to: Xuelei Ma, email: drmaxuelei@gmail.com

Keywords: small cell lung cancer (SCLC), prognostic factors, neutrophil-lymphocyte ratio (NLR), platelet-lymphocyte ratio $(P L R)$, lactate dehydrogenase $(L D H)$

Received: August 16, $2016 \quad$ Accepted: February 20, $2017 \quad$ Published: March 24, 2017

Copyright: Deng et al. This is an open-access article distributed under the terms of the Creative Commons Attribution License (CC-BY), which permits unrestricted use, distribution, and reproduction in any medium, provided the original author and source are credited.

\section{ABSTRACT}

Objectives: The neutrophil-lymphocyte ratio (NLR) and the platelet-lymphocyte ratio (PLR) have been proved to affect the prognosis of various types of cancers. However, the prognostic role of NLR and PLR in patients with small-cell lung cancer (SCLC) remains controversial. The objective of this study is to assess the prognostic values of NLR, PLR and other potential prognostic indexes in SCLC patients.

Results: The optimal cutoff levels were 2.65 for NLR, 125 for PLR and 210 for LDH by ROC curves analysis. Patients in the NLR $\geq 2.65$ and LDH $\geq 210$ groups were significantly correlated with worse PFS and OS. However, patients in the PLR $<125$ group presented longer PFS time than patients in the PLR $\geq 125$ group. Multivariate analysis showed that NLR $\geq 2.65$ was an independent risk factor for both PFS $(H R=1.38 ; 95 \%$ CI 1.04-1.83; $P=0.027)$ and OS $(H R=1.35 ; 95 \%$ CI 1.02-1.79; $P=0.039$ ). $\mathrm{LDH}$ and the clinical stage were independent prognostic factors for PFS in SCLC patients. LDH, surgery history, thoracic RT and PCI were independent prognostic factors for OS.

Materials and Methods: 320 patients with SCLC were enrolled in this research from 2007 to 2014. Data was acquired through patients' medical records and followups. Receiver operating curve (ROC) was used to determine the optimal cut-off levels of NLR, PLR and lactate dehydrogenase (LDH). The Kaplan-Meier univariate analysis and multivariate Cox regression analysis were used to evaluate the impact of the NLR, PLR and other potential prognostic factors on overall survival (OS) and progressivefree survival (PFS).

Conclusions: Pretreatment elevated NLR and LDH were independent factors for poor prognosis in SCLC patients. High PLR was associated with poor PFS, but it was not an independent prognostic factor for PFS and OS.

\section{INTRODUCTION}

Lung cancer is a serious health problem with a current 5-year relative survival of $18 \%$ [1]. In recent decades, molecular-targeted therapies have been developed and have provided significant benefits for nonsmall cell lung cancer (NSCLC) patients in prolonging their OS [2]. However, there has been a distinct paucity of breakthroughs in the treatment of SCLC [3]. The median and 5-year survival rates have not significantly improved over the past 15 years for patients with SCLC [4]. Therefore, it is essential for us to explore simple and accessible prognostic factors for SCLC.

Emerging evidences have confirmed that the inflammatory response plays a crucial role in tumor progression. NLR is known as a systemic inflammatory marker which is calculated by dividing the circulating neutrophil counts by the lymphocyte counts. It has been 
proven as prognostic factors in many types of cancers, including metastatic melanoma [5], oesophageal cancer [6], colorectal cancer [7], pancreatic cancer [8], metastatic castration-resistant prostate cancer(mCRPC) [9], diffuse large B-cell lymphoma (DLBCL) [10] and NSCLC [11]. PLR is another index of systemic inflammation which is calculated by dividing the circulating platelet counts by the lymphocyte counts. Previous studies have demonstrated the prognostic role of PLR in many malignant tumors, such as breast cancer [12], nasopharyngeal cancer [13] and NSCLC [14]. However, the prognostic role of factors mentioned above in patients with small cell lung cancer (SCLC) remains controversial.

In order to evaluate the prognostic roles of NLR, PLR and other potential prognostic factors in SCLC patients with progression-free survival (PFS) and overall survival (OS), we retrospectively analyzed a large sample of patients with SCLC in this study.

\section{RESULTS}

\section{The optimal cutoff levels for elevated NLR, PLR and LDH}

In order to avoid a predetermined cutoff point, we used receiver operating curve (ROC) analysis to determine the optimal cutoff values of pretreatment NLR, PLR and $\mathrm{LDH}$ according to the maximum joint specificity and sensitivity. According to the ROC curve showed in Figure 1, the area under the ROC curves for NLR, PLR and LDH was 0.632 (95\% CI: $0.571-0.693, P<0.001)$, 0.531 (95\% CI: $0.468-0.595, P=0.332$ ) and 0.683 (95\% CI: $0.623-0.742, P<0.001)$. The optimal cutoff levels were 2.65 for NLR, 125 for PLR and 210 for LDH by ROC curves analysis.

\section{Basic characteristics of patients}

The median age of all patients was 58 (range: $24-81)$. The majority of the patients were male $(74.7 \%$, $239 / 320)$, and female patients account for $25.3 \%$ (81/320). Almost $61.9 \%(198 / 320)$ of patients were at extensive stage (ES), and $38.1 \%(122 / 320)$ of patients were in limited stage (LS). The ECOG performance status of patients is almost normal (median 1). Current or ever-smokers consisted $67.2 \%(215 / 320)$ of patients. 27 patients $(8.4 \%)$ were treated with thoracic surgery, 135 patients $(42.2 \%)$ were treated with thoracic radiotherapy (RT) and 77 patients $(24.1 \%)$ received prophylactic cranial irradiation (PCI). The median value of NLR was 3.04 (range: 0.6615.50). 123 patients $(38.4 \%)$ were in NLR $<2.65$ group and 197 patients $(61.6 \%)$ were in NLR $\geq 2.65$ group. The median value of PLR was 125.10 (range: 39.51589.06), 159 patients (49.7\%) were in PLR $<125$ group and 161 patients $(50.3 \%)$ were in PLR $\geq 125$ group. The median value of LDH was 205 (range: 104-1887).

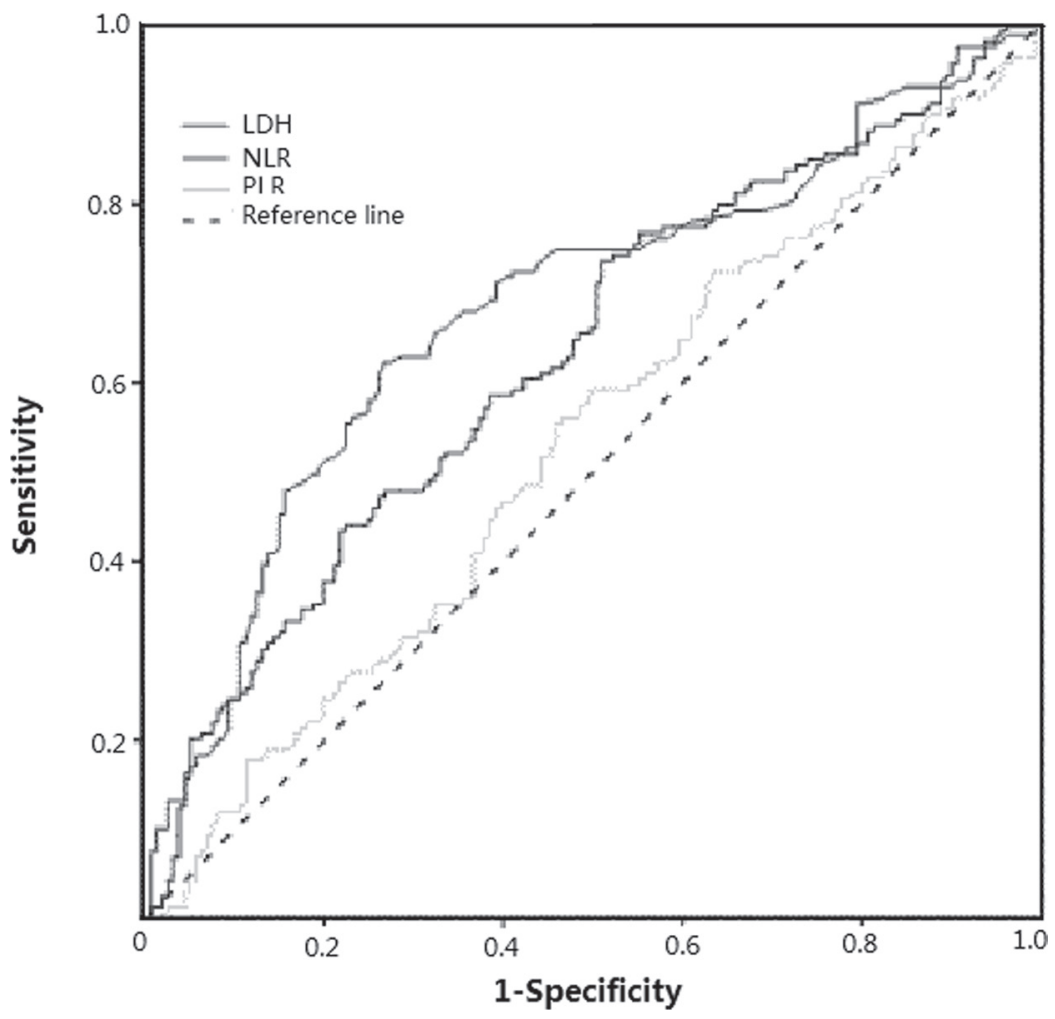

Figure 1: Receiver operating characteristic (ROC) curves of pretreatment NLR, PLR and LDH for predicting survival in patients with SCLC after treatments. 
169 patients $(52.8 \%)$ were in $\mathrm{LDH}<210$ group and 151 patients $(47.2 \%)$ were in $\mathrm{LDH} \geq 210$ group. The median PFS and median OS of all the patients were 7.65 months (range: 0-80) and 13.8 months (range: 0.6-80, respectively). The correlation between NLR, PLR and clinical factors of SCLC patients were shown in Table 1. Our study revealed that NLR was prominently associated with tumor stage, PS, LDH, surgery, and RT. PLR was closely associated with the gender, history of tobacco, LDH and RT, separately.

\section{PFS and OS according to NLR, PLR and LDH status}

As is shown in Table 2, in the NLR $<2.65$ group, the 1-, 2-, and 3-year PFS rates separately were 41.7, 22.0 and $9.8 \%$, while in the NLR $\geq 2.65$ group, the PFS rates were 19.8, 7.7 and 3.6\% (Figure 2A). In the PLR $<125$ group, the 1-, 2-, and 3-year PFS rates were 35.4, 7.6 and $2.5 \%$, and in the PLR $\geq 125$ group, the PFS rates were $20.4,8.6$ and $4.3 \%$ (Figure $2 \mathrm{~B}$ ). In the $\mathrm{LDH}<210$, the $1-$, 2-, and 3-year PFS rates were 40.2, 20.7 and 4.1\%, while in the $\mathrm{LDH} \geq 210$ group, the PFS rates were 13.9, 4.7 and $0.7 \%$ (Figure 2C). Correspondingly, the 1-, 2-, and 3-year OS rates were $74.8,35.8$ and $17.1 \%$ in the NLR $<2.65$ group and $51.3,18.8$ and $8.6 \%$ in the NLR $\geq 2.65$ group, separately (Figure 3A). The 1-, 2-, and 3-year OS rates were $63.3,27.9$ and $12.7 \%$ in the PLR $<125$ group and $57.4,22.8$ and $10.5 \%$ in the PLR $\geq 125$ group (Figure $3 B$ ). The 1-, 2-, and 3-year OS rates were 74.0, 35.5 and 18.3\% in the $\mathrm{LDH}<210$ group and 45.0, 13.9 and $4.6 \%$ in the $\mathrm{LDH} \geq 210$ group (Figure 3C). On a whole, PFS and OS of patients in the NLR $<2.65$ and $\mathrm{LDH}<210$ group were obviously improved compared with patients in the NLR
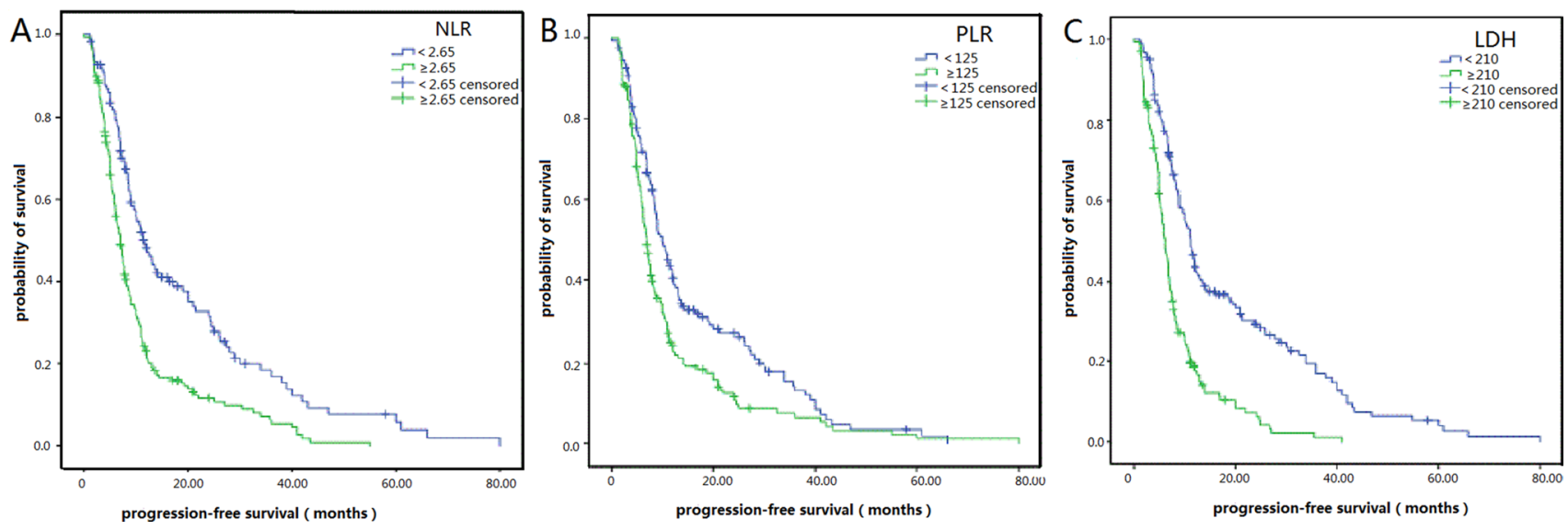

Figure 2: Kaplan-Meier survival curves for progression-free survival (PFS) in SCLC patients after diagnoses. (A) PFS of patients with NLR $<2.65$ was longer than those with NLR $\geq 2.65$. $(P<0.001, \log$-rank). (B) PFS of patients with PLR $<125$ was longer than those with PLR $\geq 125$. ( $P=0.001, \log$-rank). (C) PFS of patients with $\mathrm{LDH}<210$ was longer than those with $\mathrm{LDH} \geq 210$. $(P<0.001, \log -$ rank $)$.
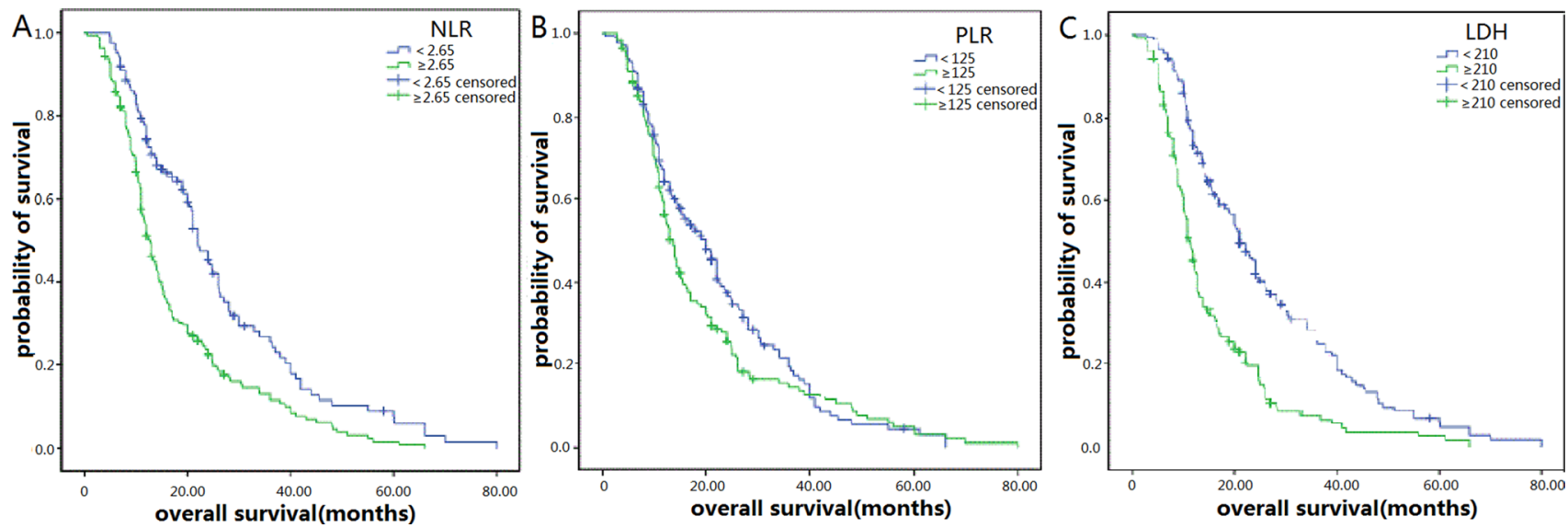

Figure 3: Kaplan-Meier survival curves for overall survival (OS) in patients with SCLC after diagnoses. (A) OS of patients with NLR $<2.65$ was also longer than those with NLR $\geq 2.65$. ( $P<0.001$, log-rank). (B) OS of patients with PLR $<125$ was not obvious different from those with PLR $\geq 125$. $(P=0.099$, log-rank).(C) OS of patients with LDH $<210$ was also longer than those with LDH $\geq 210$. $(P<0.001$, log-rank $)$. 
Table 1: Correlation between peripheral NLR/PLR and clinical variables of SCLC patients

\begin{tabular}{|c|c|c|c|c|c|c|c|}
\hline \multirow{2}{*}{ Variables } & \multirow{2}{*}{ cases } & \multicolumn{2}{|c|}{ NLR } & \multirow[b]{2}{*}{$P$} & \multicolumn{2}{|c|}{ PLR } & \multirow[b]{2}{*}{$P$} \\
\hline & & $<2.65$ & $\geq 2.65$ & & $<125$ & $\geq 125$ & \\
\hline \multicolumn{8}{|l|}{ Age (years) } \\
\hline$<55$ & 113 & 41 & 72 & & 53 & 60 & \\
\hline$\geq 55$ & 207 & 82 & 125 & 0.558 & 106 & 101 & 0.462 \\
\hline \multicolumn{8}{|l|}{ gender } \\
\hline male & 239 & 90 & 149 & & 129 & 110 & \\
\hline female & 81 & 33 & 48 & 0.622 & 30 & 51 & 0.008 \\
\hline \multicolumn{8}{|c|}{ Smoking history } \\
\hline no & 105 & 47 & 58 & & 43 & 62 & \\
\hline yes & 215 & 76 & 139 & 0.104 & 116 & 99 & 0.029 \\
\hline \multicolumn{8}{|l|}{ Clinical stage } \\
\hline LS & 122 & 61 & 61 & & 68 & 54 & \\
\hline ES & 198 & 62 & 136 & 0.001 & 91 & 107 & 0.089 \\
\hline \multicolumn{8}{|c|}{ Performance status (PS) } \\
\hline 0 & 104 & 52 & 52 & & 55 & 49 & \\
\hline$\geq 1$ & 216 & 71 & 145 & 0.003 & 104 & 112 & 0.427 \\
\hline \multicolumn{8}{|l|}{ LDH } \\
\hline$<210$ & 169 & 90 & 79 & & 101 & 68 & \\
\hline$\geq 210$ & 151 & 33 & 118 & $<0.001$ & 58 & 93 & $<0.001$ \\
\hline \multicolumn{8}{|l|}{ surgery } \\
\hline no & 293 & 105 & 188 & & 143 & 150 & \\
\hline yes & 27 & 18 & 9 & 0.002 & 16 & 11 & 0.299 \\
\hline \multicolumn{8}{|c|}{ Thoracic radiotherapy (RT) } \\
\hline no & 185 & 59 & 126 & & 82 & 103 & \\
\hline yes & 135 & 64 & 71 & 0.005 & 77 & 58 & 0.025 \\
\hline \multicolumn{8}{|c|}{ Prophylactic cranial irradiation (PCI) } \\
\hline no & 243 & 88 & 155 & & 117 & 126 & \\
\hline yes & 77 & 35 & 42 & 0.146 & 42 & 35 & 0.328 \\
\hline
\end{tabular}

$\geq 2.65$ and $\mathrm{LDH} \geq 210$ groups. However, only PFS of patients in the PLR $<125$ group were relatively longer than patients in PLR $\geq 125$ group.

\section{Prognostic factors of SCLC patients}

For all patients, PFS rates at the 1-, 2- and 3-year period respectively were $27.8,13.1$ and $5.9 \%$. OS rates at the 1-, 2- and 3-year period respectively were $60.3,25.3$ and $11.9 \%$. Univariate analysis showed that NLR $\geq 2.65$, PLR $\geq 125$, LDH $\geq 210$, age $\geq 55$, male, smoking, ESSCLC, PS $\geq 1$ and deletion of surgery or thoracic RT were associated with significantly shorter PFS in SCLC patients. Similarly, NLR $\geq 2.65, \mathrm{LDH} \geq 210$,age $\geq 55$, male, smoking, ES-SCLC, PS $\geq 1$ and patients without surgery, thoracic RT or PCI predicted worse OS (Table 2).

The Cox proportional hazard model was applied to perform multivariate analyses. The analysis revealed that $\mathrm{NLR} \geq 2.65(\mathrm{HR}=1.38 ; 95 \%$ CI $1.04-1.83 ; P=0.027)$, $\mathrm{LDH} \geq 210(\mathrm{HR}=1.56 ; 95 \%$ CI $1.18-2.07 ; P=0.002)$ and ES-SCLC (HR $=1.62 ; 95 \%$ CI 1.18-2.23; $P=0.003)$ were independent prognostic factors for PFS in patients with SCLC. Correspondingly, NLR $\geq 2.65$ ( $\mathrm{HR}=1.35$; $95 \%$ CI 1.02-1.79; $P=0.039), \mathrm{LDH} \geq 210$ (HR = 1.46; $95 \%$ CI $1.10-1.96 ; P=0.002$ ), patient with surgery $(\mathrm{HR}=0.55 ; 95 \%$ CI $0.33-0.93 ; P=0.025)$, thoracic RT $(\mathrm{HR}=0.66 ; 95 \%$ CI $0.50-0.88 ; P=0.005)$ and PCI $(\mathrm{HR}=0.71 ; 95 \%$ CI $0.53-0.96 ; P=0.023)$ were independent prognostic factors for OS in SCLC patients (Table 3).

\section{DISCUSSION}

Recently, many articles have certified that the progression of cancers was closely associated with inflammation and immunity status, and that the NLR, PLR and LDH were the easily obtained and effective markers of inflammation and immunity. However, currently there are no consistent cut off values in preexisting studies. Therefore, we determined the optimal cutoff values of 
Table 2: Prognostic factors for PFS and OS by univariate analysis

\begin{tabular}{|c|c|c|c|c|c|c|c|c|c|}
\hline \multirow{2}{*}{ variables } & \multirow{2}{*}{$n$} & \multicolumn{3}{|c|}{ PFS(year) } & \multirow[b]{2}{*}{$p$} & \multicolumn{3}{|c|}{ OS(years) } & \multirow[b]{2}{*}{$p$} \\
\hline & & 1 & 2 & 3 & & 1 & 2 & 3 & \\
\hline \multicolumn{10}{|l|}{ Age (years) } \\
\hline$<55$ & 113 & $31.9 \%$ & $16.8 \%$ & $9.7 \%$ & & $63.7 \%$ & $32.7 \%$ & $17.7 \%$ & \\
\hline$\geq 55$ & 207 & $25.6 \%$ & $11.1 \%$ & $3.9 \%$ & 0.022 & $58.5 \%$ & $21.3 \%$ & $8.7 \%$ & 0.007 \\
\hline \multicolumn{10}{|l|}{ gender } \\
\hline male & 239 & $25.1 \%$ & $11.7 \%$ & $5.4 \%$ & & $55.6 \%$ & $23.0 \%$ & $11.3 \%$ & \\
\hline female & 81 & $35.8 \%$ & $17.3 \%$ & $7.4 \%$ & 0.014 & $74.1 \%$ & $32.1 \%$ & $13.6 \%$ & 0.043 \\
\hline \multicolumn{10}{|c|}{ Smoking history } \\
\hline no & 105 & $34.3 \%$ & $17.1 \%$ & $7.6 \%$ & & $70.5 \%$ & $33.4 \%$ & $12.4 \%$ & \\
\hline yes & 215 & $24.7 \%$ & $11.1 \%$ & $5.1 \%$ & 0.010 & $55.3 \%$ & $21.4 \%$ & $11.6 \%$ & 0.027 \\
\hline \multicolumn{10}{|c|}{ Clinical stage } \\
\hline LS & 122 & $45.9 \%$ & $23.8 \%$ & $14.8 \%$ & & $72.1 \%$ & $35.3 \%$ & $18.9 \%$ & \\
\hline ES & 198 & $16.7 \%$ & $6.6 \%$ & $0.5 \%$ & $<0.001$ & $53.0 \%$ & $19.2 \%$ & $7.6 \%$ & $<0.001$ \\
\hline \multicolumn{10}{|c|}{ Performance status (PS) } \\
\hline 0 & 104 & $33.7 \%$ & $17.3 \%$ & $5.8 \%$ & & $71.2 \%$ & $32.7 \%$ & $13.5 \%$ & \\
\hline$\geq 1$ & 216 & $25.0 \%$ & $11.1 \%$ & $6.0 \%$ & 0.017 & $55.1 \%$ & $21.7 \%$ & $11.1 \%$ & 0.006 \\
\hline \multicolumn{10}{|l|}{ NLR } \\
\hline$<2.65$ & 123 & $41.7 \%$ & $22.0 \%$ & $9.8 \%$ & & $74.8 \%$ & $35.8 \%$ & $17.1 \%$ & \\
\hline$\geq 2.65$ & 197 & $19.8 \%$ & $7.7 \%$ & $3.6 \%$ & $<0.001$ & $51.3 \%$ & $18.8 \%$ & $8.6 \%$ & $<0.001$ \\
\hline \multicolumn{10}{|l|}{ PLR } \\
\hline$<125$ & 159 & $35.4 \%$ & $7.6 \%$ & $2.5 \%$ & & $63.3 \%$ & $27.9 \%$ & $12.7 \%$ & \\
\hline$\geq 125$ & 161 & $20.4 \%$ & $8.6 \%$ & $4.3 \%$ & 0.001 & $57.4 \%$ & $22.8 \%$ & $10.5 \%$ & 0.099 \\
\hline \multicolumn{10}{|l|}{$\mathrm{LDH}$} \\
\hline$<210$ & 169 & $40.2 \%$ & $20.7 \%$ & $4.1 \%$ & & $74.0 \%$ & $35.5 \%$ & $18.3 \%$ & \\
\hline$\geq 210$ & 151 & $13.9 \%$ & $4.7 \%$ & $0.7 \%$ & $<0.001$ & $45.0 \%$ & $13.9 \%$ & $4.6 \%$ & $<0.001$ \\
\hline \multicolumn{10}{|l|}{ surgery } \\
\hline no & 293 & $24.9 \%$ & $10.2 \%$ & $3.4 \%$ & & $57 \%$ & $22.2 \%$ & $9.2 \%$ & \\
\hline yes & 27 & $59.3 \%$ & $44.4 \%$ & $33.3 \%$ & $<0.001$ & $96.3 \%$ & $59.2 \%$ & $40.7 \%$ & 0.001 \\
\hline \multicolumn{10}{|c|}{ Thoracic radiotherapy (RT) } \\
\hline no & 185 & $19.5 \%$ & $9.2 \%$ & $4.3 \%$ & & $51.4 \%$ & $18.9 \%$ & $9.7 \%$ & \\
\hline yes & 135 & $39.3 \%$ & $18.5 \%$ & $8.1 \%$ & $<0.001$ & $72.6 \%$ & $34.2 \%$ & $14.8 \%$ & 0.001 \\
\hline \multicolumn{10}{|c|}{ Prophylactic cranial irradiation (PCI) } \\
\hline no & 243 & $25.4 \%$ & $10.2 \%$ & $4.9 \%$ & & $57.2 \%$ & $23.0 \%$ & $8.6 \%$ & \\
\hline yes & 77 & $35.1 \%$ & $22.1 \%$ & $9.1 \%$ & 0.052 & $70.1 \%$ & $32.5 \%$ & $22.1 \%$ & 0.005 \\
\hline
\end{tabular}

2.65 for NLR, 125 for PLR and 210 for LDH by ROC curves analysis.

As is known, the neutrophil, as a kind of inflammation cell, influences tumor initiation and progression in the tumor microenvironment [15]. It can aid the proliferation and survival of malignant cells, promote angiogenesis and metastasis, subvert adaptive immune responses, and alter responses to hormones and chemotherapeutic agents $[16,17]$. The neutrophil also increases VEGF (vascular endothelial growth factor) bioavailability and bioactivity [18], and VEGF-mediated angiogenesis is essential for tumor growth, recurrence, invasion and metastasis [19]. Moreover, multiple clinical and experimental studies have established that the lymphocyte also plays an important role in antitumor immunity $[20,21]$. The high NLR which means an increased neutrophil count or a decreased lymphocyte count indicates an imbalance in the inflammatory cascade 
Table 3: Prognostic factors for PFS and OS as determined by multivariate Cox proportional hazards regression model

\begin{tabular}{|c|c|c|c|c|c|c|}
\hline \multirow{2}{*}{ variables } & \multicolumn{2}{|c|}{ PFS } & \multirow{2}{*}{$P$} & \multicolumn{2}{|c|}{ OS } & \multirow{2}{*}{$P$} \\
\hline & HR & $95 \%$ CI & & HR & $95 \% \mathrm{CI}$ & \\
\hline Clinic stage & 1.62 & $1.18-2.23$ & 0.003 & & & \\
\hline NLR & 1.38 & $1.04-1.83$ & 0.027 & 1.35 & $1.02-1.79$ & 0.039 \\
\hline LDH & 1.56 & $1.18-2.07$ & 0.002 & 1.46 & $1.10-1.96$ & 0.010 \\
\hline Surgery & & & & 0.55 & $0.33-0.93$ & 0.025 \\
\hline Thoracic RT & & & & 0.66 & $0.50-0.88$ & 0.005 \\
\hline PCI & & & & 0.71 & $0.53-0.96$ & 0.023 \\
\hline
\end{tabular}

and immune response to malignant tumors, thus tumors recurrence and metastasis may occur more frequently in the high NLR patients [18].

In our study, we found patients with elevated NLR $(\geq 2.65)$ had obviously worse PFS and OS than those with low NLR $(<2.65)$ (Figures 2.A and 3.A, Table 2). The multivariate analysis showed NLR $\geq 2.65$ was an independent prognostic factor of worse PFS and OS. The association between NLR and prognosis in SCLC patients has also been confirmed in some other studies. For example, Shao et al. [22] found out that high NLR was a useful and easily obtained indicator for recurrence which predicted a poor prognosis for C-SCLC (combinedSCLC). Wang et al. [23] had the same opinion. Hong et al. [24] showed that high NLR predicted poor long-term prognosis in univariate analysis, but multivariate analysis showed NLR was not an independent prognostic factor in SCLC patients. However, Kang et al. [25] demonstrated that NLR was an independent prognostic factor for OS and PFS, which was consistent with our opinion.

PLR is another indicator of systemic inflammation, and some studies have demonstrated that the activation of platelets and the coagulation system are crucial to tumor metastasis. But the potential mechanisms have not been well clarified until now, some scholars hold the opinion that platelet provides a procoagulant surface to promote the enlargement of cancer-related coagulation, which can be used to shroud tumor cells, thus shielding the tumor cells from immune responses and facilitating them to grow and metastasis [26, 27]. Another opinion is that platelets are the main sources of cytokines such as VEGF and transforming growth factor $\beta$ (TGF- $\beta$ ) which have significant effect on tumor angiogenesis [28]. In a word, the high PLR means an increased platelet count or a decreased lymphocyte count, which may be associated with tumor recurrence and metastasis.

Our study showed patients with elevated PLR $(\geq 125)$ had significantly worse PFS than those with low PLR $(<125)$ (Figure 2B, Table 2), but was not associated with OS in SCLC patients (Figure 3B, Table 2), which was consistent with the finding of Zhao et al. [14] and Kang et al. [25]. The multivariate analysis showed that PLR $\geq 125$ was not an independent prognostic factor of worse PFS and OS in SCLC patients.

Earlier studies have confirmed LDH was a strong, independent predictive factor of survival in patients with SCLC [29, 30, 31]. In our study, we also found patients with elevated LDH ( $\geq 210)$ had obviously worse PFS and OS than those with low NLR $(<210)$ (Figures 2C and 3C, Table 2). The multivariate analysis showed $\mathrm{LDH} \geq 210$ was an independent prognostic factor of worse PFS and OS.

\section{MATERIALS AND METHODS}

\section{Patients}

In this retrospective study, we analyzed 320 patients with pathologically confirmed SCLC in our cancer center from March 2007 to December 2014. The median follow-up time was 39.1 months (range: 3.2-85.4). From electronic records, we extracted patient characteristics including sex, age, smoking habit, Eastern Cooperative Oncology Group (ECOG) performance status, diagnoses, treatments, outcomes and the blood results at the time of diagnosis. The primary endpoint was PFS, which was calculated from the date of first diagnosis to the onset of disease progression or the last follow-up. The second endpoint was OS, defined as the period from diagnosis to the time of death or the last follow-up.

\section{Statistical analysis}

We used SPSS statistical software (version 19.0) to analyze data, and the chi-square test to compare categorical variables. Kaplan-Meier method was used for univariate analysis. Obvious differences between groups were determined by log-rank test. The Cox proportional hazard model was applied for multivariate analysis, and hazard ratios (HRs) obtained were reported as relative risks with corresponding $95 \%$ confidence intervals (CIs). All tests were 2-sided, and $p$ value of $<0.05$ was considered statistical significant. 


\section{CONCLUSIONS}

Our study observed that elevated peripheral NLR before treatment was an independent prognostic factor of poor PFS and OS in SCLC patients. Patients in elevated PLR group had relatively shorter PFS time than those in low PLR group, but PLR was not an independent prognostic indicator of poor PFS and OS. We also found LDH and clinical stage were independent prognostic factors for PFS. Correspondingly, LDH, surgery history, thoracic RT and PCI were independent prognostic factors for OS in SCLC patients. Those findings might help clinicians to use personalized and reasonable adjuvant therapies for the patients with high risk of recurrence and metastasis after diagnose. We should note that this study is limited for it is a single-center and retrospective research. In the future, multicenter and prospective studies are needed to testify our findings.

\section{CONFLICTS OF INTEREST}

All authors declare that they have no conflicts of interest, financial or otherwise.

\section{REFERENCES}

1. Siegel RL, Miller KD, Jemal A. Cancer statistics. 2015. CA Cancer J Clin. 2015; 65:5-29.

2. Otsuka K, Hata A, Takeshita J, Okuda C, Kaji R, Masago K, Fujita S, Katakami N. EGFR-TKI rechallenge with bevacizumab in EGFR-mutant non-small cell lung cancer. Cancer Chemother Pharmacol. 2015; 76:835-41.

3. Koinis F, Kotsakis A, Georgoulias V. Small cell lung cancer (SCLC): no treatment advances in recent years. Transl Lung Cancer Res. 2016; 5:39-50.

4. Gaspar LE, McNamara EJ, Gay EG, Putnam JB, Crawford J, Herbst RS, Bonner JA. Small-cell lung cancer: prognostic factors and changing treatment over 15 years. Clin Lung Cancer. 2012; 13:115-22.

5. Cananzi FC, Dalgleish A, Mudan S. Surgical management of intraabdominal metastases from melanoma: role of the neutrophil to lymphocyte ratio as a potential prognostic factor. World J Surg. 2014; 38:1542-50.

6. Yoo EJ, Park JC, Kim EH, Park CH, Shim CN, Lee HJ, Chung HS, Lee H, Shin SK, Lee SK, Lee CG, Lee YC. Prognostic value of neutrophil-to-lymphocyte ratio in patients treated with concurrent chemoradiotherapy for locally advanced oesophageal cancer. Digestive and liver disease. 2014; 46:846-853.

7. Azab B, Mohammad F, Shah N, Vonfrolio S, Lu W, Kedia $\mathrm{S}$, Bloom SW. The value of the pretreatment neutrophil lymphocyte ratio vs. platelet lymphocyte ratio in predicting the long-term survival in colorectal cancer. Cancer Biomark. 2014; 14:303-12.
8. Yang JJ, Hu ZG, Shi WX, Deng T, He SQ, Yuan SG. Prognostic significance of neutrophil to lymphocyte ratio in pancreatic cancer: a meta-analysis. World J Gastroenterol. 2015; 21:2807-15.

9. Templeton AJ, Pezaro C, Omlin A, McNamara MG, Leibowitz-Amit R, Vera-Badillo FE, Attard G, de Bono JS, Tannock IF, Amir E. Simple prognostic score for metastatic castration-resistant prostate cancer with incorporation of neutrophil-to-lymphocyte ratio. Cancer. 2014; 120:3346-52.

10. Troppan K, Deutsch A, Gerger A, Stojakovic T, BehamSchmid C, Wenzl K, Neumeister P, Pichler M. The derived neutrophil to lymphocyte ratio is an independent prognostic factor in patients with diffuse large B-cell lymphoma. Br J Cancer. 2014; 110:369-74.

11. Zhang H, Xia H, Zhang L, Zhang B, Yue D, Wang C. Clinical significance of preoperative neutrophil-lymphocyte vs platelet-lymphocyte ratio in primary operable patients with non-small cell lung cancer. Am J Surg. 2015; 210:526-35.

12. Koh CH, Bhoo-Pathy $\mathrm{N}, \mathrm{Ng} \mathrm{KL}$, Jabir RS, Tan GH, See MH, Jamaris S, Taib NA. Utility of pre-treatment neutrophil-lymphocyte ratio and platelet-lymphocyte ratio as prognostic factors in breast cancer. Br J Cancer. 2015; 113:150-58.

13. Jiang R, Zou X, Hu W, Fan YY, Yan Y, Zhang MX, You R, Sun R, Luo DH, Chen QY, Huang PY, Hua YJ, Guo L, Chen MY. The elevated pretreatment platelet-to-lymphocyte ratio predicts poor outcome in nasopharyngeal carcinoma patients. Tumour Biol. 2015; 36:7775-87.

14. Zhao QT, Yuan Z, Zhang H, Zhang XP, Wang HE, Wang ZK, Duan GC. Prognostic role of platelet to lymphocyte ratio in non-small cell lung cancers: A meta-analysis including 3,720 patients. Int J Cancer. 2016; 139:164-70.

15. Grange JM, Krone B, Mastrangelo G. Infection, inflammation and cancer. Int J Cancer. 2011; 128:2240-41.

16. Moore MM, Chua W, Charles KA, Clarke SJ. Inflammation and cancer: causes and consequences. Clin Pharmacol Ther. 2010; 87:504-08.

17. Mantovani A, Allavena P, Sica A, Balkwill F. Cancer-related inflammation. Nature. 2008; 454:436-44.

18. Li X, Han Z, Cheng Z, Yu J, Liu S, Yu X, Liang P. Preoperative neutrophil-to-lymphocyte ratio is a predictor of recurrence following thermal ablation for recurrent hepatocellular carcinoma: a retrospective analysis. PLoS One. 2014; 9:e110546.

19. Wang W, Ma XP, Shi Z, Zhang P, Ding DL, Huang HX, Saiyin HG, Chen TY, Lu PX, Wang NJ, Yu H, Sun J, Zheng SL, et al. Epidermal growth factor receptor pathway polymorphisms and the prognosis of hepatocellular carcinoma. Am J Cancer Res. 2014; 5:396-410.

20. Dong Y, Richards JA, Gupta R, Aung PP, Emley A, Kluger Y, Dogra SK, Mahalingam M, Wajapeyee N. PTEN functions as a melanoma tumor suppressor by promoting host immune response. Oncogene. 2014; 33:4632-42. 
21. Nagai S, Abouljoud MS, Kazimi M, Brown KA, Moonka D, Yoshida A. Peritransplant Lymphopenia Is a Novel Prognostic Factor in Recurrence of Hepatocellular Carcinoma After Liver Transplantation. Transplantation. 2014; 97:694-701. doi: 10.1097/01.TP.0000437426.15890.1d.

22. Shao N, Cai Q. High pretreatment neutrophil-lymphocyte ratio predicts recurrence and poor prognosis for combined small cell lung cancer. Clinical \& translational oncology. 2015; 17:772-778.

23. Wang $\mathrm{X}$, Jiang $\mathrm{R}$, Li K. Prognostic significance of pretreatment laboratory parameters in combined small-cell lung cancer. Cell Biochem Biophys. 2014; 69:633-40.

24. Hong X, Cui B, Wang M, Yang Z, Wang L, Xu Q. Systemic Immune-inflammation Index, Based on Platelet Counts and Neutrophil-Lymphocyte Ratio, Is Useful for Predicting Prognosis in Small Cell Lung Cancer. Tohoku J Exp Med. 2015; 236:297-304.

25. Kang MH, Go SI, Song HN, Lee A, Kim SH, Kang JH, Jeong BK, Kang KM, Ling H, Lee GW. The prognostic impact of the neutrophil-to-lymphocyte ratio in patients with small-cell lung cancer. Br J Cancer. 2014; 111:452-60.
26. Bambace NM, Holmes CE. The platelet contribution to cancer progression. J Thromb Haemost. 2011; 9:237-49.

27. Gay LJ, Felding-Habermann B. Contribution of platelets to tumour metastasis. Nat Rev Cancer. 2011; 11:123-34.

28. Pinedo HM, Verheul HM, D'Amato RJ, Folkman J. Involvement of platelets in tumour angiogenesis? Lancet. 1998; 352:1775-77.

29. Sagman U, Feld R, Evans WK, Warr D, Shepherd FA, Payne D, Pringle J, Yeoh J, DeBoer G, Malkin A. The prognostic significance of pretreatment serum lactate dehydrogenase in patients with small-cell lung cancer. J Clin Oncol. 1991; 9:954-61.

30. Buccheri G, Ferrigno D, and Cuneo Lung Cancer Study Group. Serum biomarkers of non-neuron-endocrine origin in small-cell lung cancer: a 16-year study on carcinoembryonic antigen, tissue polypeptide antigen and lactate dehydrogenase. Lung Cancer. 2000; 30:37-49.

31. Hermes A, Gatzemeier U, Waschki B, Reck M. Lactate dehydrogenase as prognostic factor in limited and extensive disease stage small cell lung cancer - a retrospective single institution analysis. Respir Med. 2010; 104:1937-42. 